\title{
The association of triglyceride and glucose index, triglyceride to high density lipoprotein cholesterol ratio with prehypertension and hypertension in normoglycemic subjects: a large cross-sectional population study
}

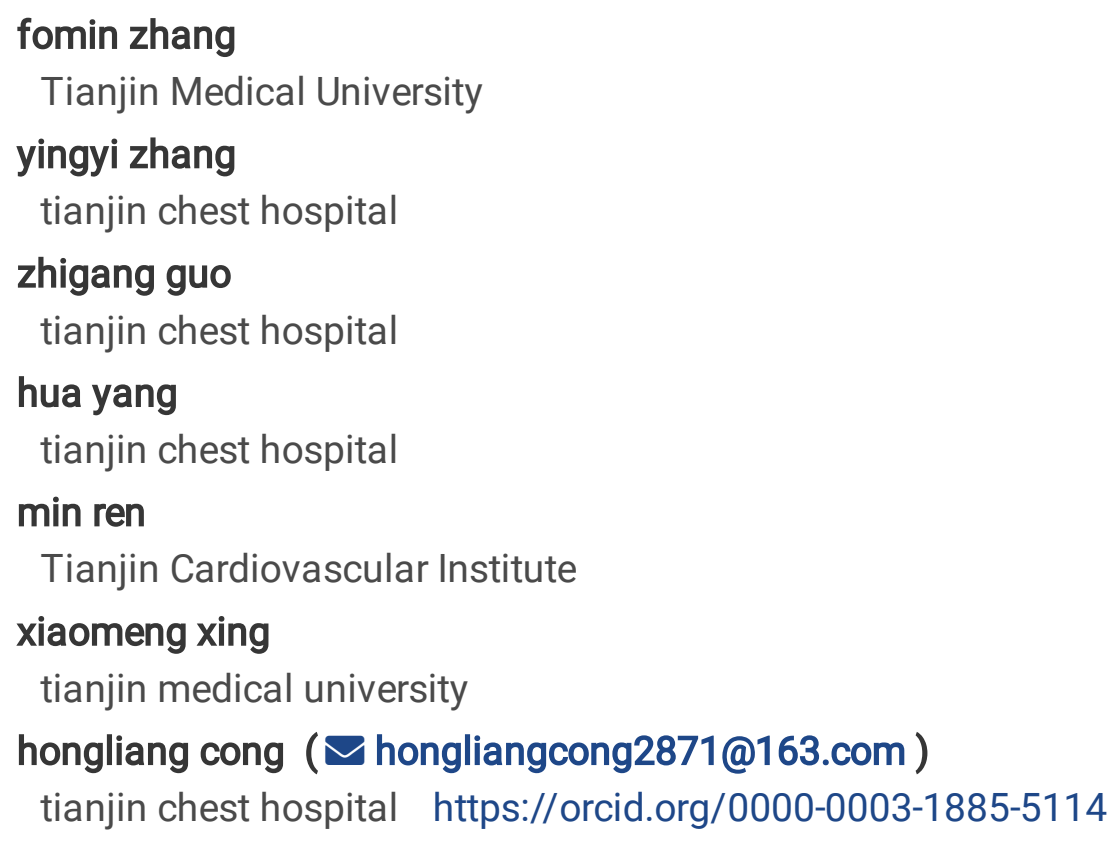

Research article

Keywords: Insulin resistance, Hypertension, Prehypertension, Triglyceride and glucose index, Triglyceride to high density lipoprotein cholesterol ratio

Posted Date: March 10th, 2021

DOI: https://doi.org/10.21203/rs.3.rs-302472/v1

License: (1) This work is licensed under a Creative Commons Attribution 4.0 International License. Read Full License 


\section{Abstract \\ Background}

Triglyceride and glucose index (TYG) and triglyceride to high density lipoprotein cholesterol ratio (TG/HDL-c) not only were significant association with hypertension, but also were related to prehypertension. However, few of these studies have large subjects to study the relationship between TyG ,TG/HDL and hypertension, prehypertension in the same population. Therefore, We conducted a large cross-sectional study to explore the association of TG/HDL-c, TyG index with prehypertension and hypertension in the same normoglycemic subjects from China, Tianjin .

\section{Methods}

A total of 32,124 adults were eligible for this study. According to the level of blood pressure, the enrolled individuals were divided into three groups, Which were normotension, prehypertension and hypertension. All participants completed a questionnaire, followed by a physical examination and blood sample test. Spearman's correlation analysis was used to determine the correlation between TyG index, TG/HDL-c and their related parameters, Multiple Logistic regression analyses were applied to explore the association of TyG indexes and TG/HDL quartiles with prehypertension and hypertension.

\section{Results}

The association between TyG index ,TG/HDL-c and age, heart rate(HR),Body Mass Index(BMI), systolic blood pressure(SBP), diastolic blood pressure(DBP), total cholesterol(TC), triglycerides(TG), LDL-cholesterol(LDL-c), fasting glucose(GLU) were positive correlation, while HDL-cholesterol(HDL-c) was negative correlation in spearman correlation analysis $(p<0.001)$. In multiple logistic regression analysis, there was a significant difference in the risk of prehypertension and hypertension when comparing the highest TyG index to the lowest TyG index and corresponding ORs were $1.795(1.638,1.968)$ and $2.439(2.205,2.698)$, respectively. For TG/HDL-C, the corresponding ORs were 1.514(1.382,1.658) and 1.934(1.751,2.137), respectively. Furthermore, When comparing the fourth quartile to the first quartile of TyG and TG/HDL, respectively, and both corresponding ORs of hypertension were higher than prehypertension.

\section{Conclusions}

Elevated TyG index and TG/HDL-c levels were associated with an increased risk of incident Prehypertension and Hypertension in normoglycemic individuals. They have the potential to become cost-effective and complementary monitors in the hierarchical management of prehypertension and hypertension.

\section{Background}

Essential hypertension is usually clustered with other cardiovascular risk factors, such as aging, obesity, insulin resistance, diabetes and hyperlipidemia. [1] A large number of clinical and epidemiological evidence shows that 
insulin resistance is closely related to hypertension. The coexistence of insulin resistance and hypertension can lead to a significant increase in the risk of cardiovascular disease and type 2 diabetes mellitus(DM2).[2]

Although hyperinsulinemic-euglycemic clamp (HIEC) technique is the gold standard of insulin resistance (IR), it is complicated, painful, and unachievable.[3] Homeostasis model assessment for IR (HOMA-IR) index is an indirect method, which need to measure insulin, so it is difficult to repeat the same results.[4-6] Therefore, a new index of insulin resistance is needed. At present, many studies evidenced that some simple routine biochemical indexes, such as the ratio of triglyceride to high density lipoprotein cholesterol (TG/HDL-c), the product of fasting triglyceride and glucose index (TYG), which can be calculated as non-insulin insulin resistance indicators and are more accurate and practical. $[7,8]$

Luis E. Simental-Mendía et al. proved that elevated TyG index is significantly associated with the presence of prehypertension and hypertension in children and adolescents.[9] Hyungseon Yeom et al. suggested that High TG/HDL-C ratio in adolescence is associated with hypertension in early adulthood.[10] However, few of these studies have large samples to study the relationship between non-insulin insulin resistance indicators and hypertension, prehypertension in the same population. [6, 9-16] Therefore, We conducted a large cross-sectional study to explore the association of TG/HDL ratio, TyG index with prehypertension and hypertension in the same normoglycemic subjects from China, Tianjin .

\section{Material And Methods}

\subsection{Subjects}

The data were collected from the early screening population of Ministry of Finance and the National Health and Family Planning Commission in 2018. Screening objects were permanent residents in the jurisdictions aged 3575. Of the 43,298 adults with initial data, individuals taking hypoglycemic drugs, lipid-lowering drugs, fasting blood-glucose $\geq 7.0 \mathrm{mmol} / \mathrm{L}$, and information incomplete were excluded. Finally, 32,124 adults remained eligible for this study. According to the level of blood pressure, the enrolled individuals were divided into three groups, Which were normotension, prehypertension and hypertension. This study was performed in accordance with the Helsinki Declaration of 1964 and its later amendments and approved by the ethics committee of Tianjin Chest Hospital. All participants provided written informed consent to participate in the study.

\subsection{Clinical Measurements}

The questionnaire were used to survey the general characteristics including age, gender, smoking history, drinking history, marital status, family history and medication etc. According to the routine protocol, a complete physical examination, including measurement of the patients' height, weight and blood pressure, was carried out. Weight $(\mathrm{kg})$ and height $(\mathrm{m})$ were measured with patients wearing only underwear. The body mass index (BMI) was calculated. The systolic blood pressure (SBP) and diastolic blood pressure (DBP) and heart rate (HR) were measured twice with a electronic sphygmomanometer after 5 minutes of rest, Two blood pressure measurements were recorded at 5-min intervals, the means were used for the data analysis.

The blood samples of individuals were collected after at least of 8 hours of overnight fasting. Serum levels of triglyceride (TG),total cholesterol (TC), low-density lipoprotein cholesterol (LDL-c), high-density lipoprotein cholesterol (HDL-c) and fasting plasma glucose (FPG) were measured by a biochemical auto-analyzer. 


\subsection{Definition}

Normotension was defined as systolic BP $(\mathrm{SBP})<120 \mathrm{mmHg}$ and diastolic BP (DBP) $<80 \mathrm{mmHg}$. Prehypertension was defined as $120 \leq \mathrm{SBP}<140 \mathrm{mmHg}$ and/or $80 \leq \mathrm{DBP}<90 \mathrm{mmHg}$. Hypertension was defined as SBP $\geq 140 \mathrm{mmHg}$ and/or DBP $\geq 90 \mathrm{mmHg}$, or use antihypertension medication currently.[17] TG/HDL-c ratio was calculated as TG $(\mathrm{mg} / \mathrm{dl}) / \mathrm{HDL}-\mathrm{c}(\mathrm{mg} / \mathrm{dl})$. TyG was calculated as the $\mathrm{Ln}[\mathrm{TG}(\mathrm{mg} / \mathrm{dl}) \times \mathrm{FPG}$ $(\mathrm{mg} / \mathrm{dl}) / 2] .[18,19] \mathrm{BMl}$ was calculated as weight $(\mathrm{kg}) / \mathrm{height2}(\mathrm{m})$.

\subsection{Statistical analysis}

The data was analyzed by using SPSS version 25.0 for windows. The Kolmogorov-Smirnov normality test was performed to determine if the data were distributed normally or not. The continuous variables of non-normal distribution were expressed as medians [interquartile range (IQR)], and the categorical variables were expressed as frequencies [percentages (\%)].Continuous variables were compared using the Kruskal-Wallis $\mathrm{H}$ test, Categorical variables among groups were compared using Chi-squared test.

Spearman's correlation analysis was used to determine the correlation between TyG index, TG/HDL-c and their related parameters. Univariate logistic analysis was used to evaluate the association between each parameters and the risk of prehypertension and hypertension. Multiple Logistic regression analyses were applied to explore the association of TyG indexes and TG/HDL-c with prehypertension and hypertension.TG/HDL-c and TyG index were divided into four quartiles and the lowest quartile was used as a reference, and age, gender, smoking, drinking, marital status, BMI were adjusted as Model1. The classifications of TyG index and TG/HDL-C were as follows: quartile 1(Q1) ( $\leq 8.48)$, quartile 2(Q2) (8.49-8.76), quartile 3(Q3) (8.77-9.12), and quartile 4(Q4) ( $\geq$ 9.13) for TyG; and quartile 1(Q1) ( 1.74$)$, quartile 2(Q2) (1.75-2,49), quartile 3(Q3) (2.50-3.63), and quartile $4(\mathrm{Q} 4)$ ( $\geq 3.64$ ) for TG/HDL-c. For a statistical inference, all $p$ values are bilateral, and a $p$ value of less than 0.05 was considered statistically significant.

\section{Results}

\subsection{Descriptive statistics}

Based on the status of their blood pressure, eligible study participants $(n=32124)$ were classified into three groups: normotension $(n=7248)$, prehypertension $(n=13343)$, and hypertension $(n=11533)$. Baseline characteristics of three groups with blood pressure are shown in Table1. Significant differences in age, gender, marital status, smoking, drinking, HR, BMI, SBP, DBP, TC, TG, HDL-C, LDL-C, GLU between the groups were observed $(p<0.001)$. The age of prehypertension (56.6) was higher than normotension(52.1) and hypertension(51.5). Individuals of hypertension showed significantly higher levels of SBP and DBP than the prehypertension and normotension. With the increasing trend of blood pressure in Normotension,

prehypertension and hypertension, the percentages or medians of smoking, drinking, HR, BMI, TC, TG, LDL-C and GLU were rising, While the median of HDL-c was descending. 
Table 1

The clinical characteristics of normotension, prehypertension and hypertension

\begin{tabular}{|c|c|c|c|c|}
\hline variables & $\begin{array}{l}\text { Normotension } \\
(n=7248)\end{array}$ & $\begin{array}{l}\text { Prehypertension } \\
(n=13343)\end{array}$ & $\begin{array}{l}\text { Hypertension } \\
(n=11533)\end{array}$ & P-value \\
\hline Age & $52.1(44.8,61.7)$ & $56.6(47.9,65.5)$ & $51.5(43.3,61.9)$ & $<0.001$ \\
\hline Gender(men) & $2045(28.2 \%)$ & $5578(41.8 \%)$ & $4751(41.2 \%)$ & $<0.001$ \\
\hline Marital status & & & & $<0.001$ \\
\hline Not married & $108(1.5 \%)$ & $120(0.9 \%)$ & $115(1.0 \%)$ & \\
\hline Married & 6928(95.6\%) & $12879(96.5 \%)$ & 10743(93.2\%) & \\
\hline Divorced & $78(1.1 \%)$ & $85(0.6 \%)$ & $97(0.8 \%)$ & \\
\hline Widowed & $134(1.8 \%)$ & $259(1.9 \%)$ & $578(5.0 \%)$ & \\
\hline Smoking & $890(12.3 \%)$ & 1785(13.4\%) & $2440(21.2 \%)$ & $<0.001$ \\
\hline Drinking & $1101(15.2 \%)$ & $2237(16.8 \%)$ & $3113(27.0 \%)$ & $<0.001$ \\
\hline HR(bpm) & $72.5(68.0,78.5)$ & 73.0(70.0,78.5) & $75.0(69.0,82.0)$ & $<0.001$ \\
\hline BMI(kg/m2) & $23.6(22.0,25.6)$ & $24.6(22.9,26.7)$ & $26.3(24.1,28.7)$ & $<0.001$ \\
\hline SBP(mmHg) & $112.5(107.0,116.5)$ & $127.0(122.0,131.0)$ & $147.5(139.0,160.0)$ & $<0.001$ \\
\hline $\mathrm{DBP}(\mathrm{mmHg})$ & $70.5(65.5,74.00)$ & $79.0(73.5,82.0)$ & $85.0(78.0,92.0)$ & $<0.001$ \\
\hline $\mathrm{TC}(\mathrm{mg} / \mathrm{dl})$ & $163.32(139.83,190.47)$ & $171.39(145.33,192.31)$ & $176.16(147.17,209.19)$ & $<0.001$ \\
\hline TG(mg/dl) & 119.48(93.81,147.80) & $129.21(98.24,177.89)$ & $140.72(103.55,198.24)$ & $<0.001$ \\
\hline HDL-c(mg/dl) & $53.41(46.44,65.02)$ & $53.02(45.66,65.79)$ & $51.47(43.34,61.92)$ & $<0.001$ \\
\hline LDL-c(mg/dl) & $96.75(76.63,115.33)$ & 104.49(81.27,116.87) & $107.50(82.04,130.03)$ & $<0.001$ \\
\hline GLU(mg/dl) & $97.20(90.00,104.40)$ & $97.20(91.80,104.40)$ & $102.60(95.40,109.80)$ & $<0.001$ \\
\hline Tyg & $8.65(8.41,8.90)$ & $8.75(8.46,9.10)$ & $8.88(8.56,9.24)$ & $<0.001$ \\
\hline TG/HDL & $2.23(1.61,2.96)$ & $2.47(1.74,3.54)$ & $2.78(2.86,4.14)$ & $<0.001$ \\
\hline \multicolumn{5}{|c|}{$\begin{array}{l}\text { SBP: systolic blood pressure; DBP: diastolic blood pressure; TC: total cholesterol; TG: triglycerides; HDL-c: } \\
\text { high density lipoprotein cholesterol; LDL-C: low density lipoprotein cholesterol; GLU: fasting glucose;. BMI: } \\
\text { Body Mass Index; HR: heart rate; age, HR, BMI, SBP, DBP, TC, TG, HDL-C, LDL-c, GLU were described as } \\
\text { medians [interquartile range (IQR)]; gender, marital status, smoking, drinking as frequencies [percentages (\%)] }\end{array}$} \\
\hline
\end{tabular}

\subsection{Correlation analysis}

As shown in Table 2, the association between TyG index ,TG/HDL-c and age, HR, BMI, SBP, DBP, TC, TG, LDL-c and GLU were positive correlation, while HDL-c was negative correlation in spearman correlation analysis $(p<$ 0.001). 
Table 2

Spearman correlation between TG/HDL-C ratio, TyG index and clinical/laboratory parameters

\begin{tabular}{|lll|}
\hline parameters & $\begin{array}{l}\text { TyG TG/HDL } \\
\text { r P value r p value }\end{array}$ \\
\hline Age & $0.078<0.001$ & $0.027<0.001$ \\
\hline SBP & $0.184<0.001$ & $0.15<0.001$ \\
\hline DBP & $0.15<0.001$ & $0.166<0.001$ \\
\hline TC & $0.155<0.001$ & $0.105<0.001$ \\
\hline TG & $0.969<0.001$ & $0.848<0.001$ \\
\hline HDL-C & $-0.148<0.001$ & $-0.592<0.001$ \\
\hline LDL-C & $0.155<0.001$ & $0.105<0.001$ \\
\hline GLU & $0.350<0.001$ & $0.157<0.001$ \\
\hline BMI & $0.226<0.001$ & $0.249<0.001$ \\
\hline HR & $0.098<0.001$ & $0.067<0.001$ \\
\hline $\begin{array}{l}\text { TyG: fasting triglyceride and glucose; TG/HDL-c: triglyceride to high density lipoprotein cholesterol ; SBP: } \\
\text { systolic blood pressure; DBP: diastolic blood pressure; TC: total cholesterol; TG: triglycerides; HDL-C: high } \\
\text { density lipoprotein cholesterol; LDL-C: low density lipoprotein cholesterol; GLU: fasting glucose; } \text { BMl: Body } \\
\text { Mass Index; HR: heart rate; }\end{array}$ \\
\hline
\end{tabular}

\subsection{Univariate logistic analysis}

The Table 3 described age, gender, marital status, smoking, drinking, BMI, TyG, TG/HDL-c were significant related with prehypertension and hypertension in Univariate logistic analysis. Meanwhile, TyG index and TG/HDL-c were calculated as continuous variables. 
Table 3

clinical/laboratory parameters Univariate logistic analysis with the risk of prehypertension and hypertension

\begin{tabular}{|c|c|c|c|c|}
\hline variables & prehypertension & & hypertension & \\
\hline & OR(95\%Cl) & $P$ values & $\mathrm{OR}(95 \% \mathrm{Cl})$ & $P$ values \\
\hline Age & $1.031(1.028,1.034)$ & $<0.001$ & $1.094(1.091,1.098)$ & $<0.001$ \\
\hline Gender(men) & $1.828(1.718,1.944)$ & $<0.001$ & $1.782(1.673,1.899)$ & $<0.001$ \\
\hline \multicolumn{5}{|l|}{ Marital status } \\
\hline married & $1.673(1.288,2.173)$ & $<0.001$ & $1.456(1.118,1.897)$ & 0.005 \\
\hline divorced & $0.981(0.656,1.467)$ & 0.925 & $1.168(0.785,1.738)$ & 0.444 \\
\hline widowed & $1.740(1.247,2.428)$ & 0.001 & $4.051(2.933,5.595)$ & $<0.001$ \\
\hline Smoking & $1.103(1.012,1.202)$ & $<0.001$ & $1.917(1.764,2.083)$ & $<0.001$ \\
\hline Drinking & $1.125(1.040,1.217)$ & 0.003 & $2.064(1.913,2.228)$ & $<0.001$ \\
\hline BMI & $1.121(1.110,1.132)$ & $<0.001$ & $1.300(1.287,1.314)$ & $<0.001$ \\
\hline TyG & $1.710(1.605,1.822)$ & $<0.001$ & $2.873(2.691,3.068)$ & $<0.001$ \\
\hline TG/HDL & $1.152(1.130,1.174)$ & $<0.001$ & $1.293(1.268,1.318)$ & $<0.001$ \\
\hline
\end{tabular}

\subsection{Multiple Logistic regression analyses}

Multiple Logistic regression analyses were applied to explore the association of TyG index and TG/HDL-c with prehypertension and hypertension. TG/HDL-C and TyG index were divided into four quartiles and the lowest quartile was used as a reference, and age, gender, smoking, drinking, marital status, Body Mass Index were adjusted as Model1. The Model1 analysis of Table4 showed that the risk of incident prehypertension was 1.795 times higher in those in the fourth quartile at baseline (95\% Cl: 1.638-1.968), and 1.091 times in those in the third quartile (95\% Cl: $1.006-1.183)$, while it is no significant difference in the second quartile .Besides, the risk of incident hypertension was 2.439 times higher in those in the fourth quartile at baseline (95\% Cl: 2.205-2.698), and 1.289 times in those in the third quartile $(95 \% \mathrm{Cl}: 1.175-1.415)$, while it is no significant difference in the second quartile. And we can see that in Fig. 1, the OR of corresponding TyG index quartiles in hypertension were higher than prehypertension. 
Table 4

Association between the TyG index quartiles and risk of incident prehypertension and hypertension

\begin{tabular}{|c|c|c|c|c|c|}
\hline Variables & Quartie1 & Quartile2 & Quartile3 & Quartile4 & $\begin{array}{l}\mathrm{P} \text { for } \\
\text { trend }\end{array}$ \\
\hline \multicolumn{6}{|c|}{ Prehypertension } \\
\hline Unadjusted & 1.000(ref) & $1.017(0.943,1.096)$ & $1.229(1.136,1.328) *$ & $2.136(1.956,2.333) \star$ & $\begin{array}{l}< \\
0.001\end{array}$ \\
\hline Model 1 & 1.000 (ref) & $0.955(0.884,1.032)$ & $1.113(1.027,1.207) \star$ & $1.876(1.713,2.055) *$ & $\begin{array}{l}< \\
0.001\end{array}$ \\
\hline \multicolumn{6}{|c|}{ Hypertension } \\
\hline Unadjusted & 1.000 (ref) & $\begin{array}{l}1.157(1.066- \\
1.256)^{\star}\end{array}$ & $\begin{array}{l}1.845(1.699- \\
2.003)^{\star}\end{array}$ & $\begin{array}{l}3.889(3.551- \\
4.258)^{\star}\end{array}$ & $\begin{array}{l}<.001 \\
0.00\end{array}$ \\
\hline Model 1 & 1.000(ref) & $0.973(0.889,1.066)$ & $1.377(1.257,1.510) *$ & $2.701(2.445,2.983) *$ & $\begin{array}{l}< \\
0.001\end{array}$ \\
\hline
\end{tabular}

The Model1 analysis of Table 5 showed that the risk of incident prehypertension was 1.891 times higher in those in the fourth quartile at baseline ( $95 \% \mathrm{Cl}$ : 1.734-2.063), while it is no significant difference in the third and second quartile .Moreover, the risk of incident hypertension was 1.934 times higher in those in the fourth quartile at baseline (95\% Cl: 1.751-2.137), while it is no significant difference in the third and second quartile. And we can see that in Fig. 2, The ORs of corresponding TG/HDL-c quartiles in hypertension were higher than prehypertension. These findings indicated that a higher TyG index and TG/HDL-C are associated with an increased risk of subsequent incident hypertension.

Table 5

Association between the TG/HDL quartiles and risk of incident prehypertension and hypertension

\begin{tabular}{|c|c|c|c|c|c|}
\hline Variables & Quartile1 & Quartille2 & Quartile3 & Quartile4 & $\begin{array}{l}\mathrm{P} \text { for } \\
\text { trend }\end{array}$ \\
\hline \multicolumn{6}{|c|}{ Prehypertension } \\
\hline Unadjusted & 1.000(ref) & $\begin{array}{l}1.091(1.011- \\
1.178)^{\star}\end{array}$ & $\begin{array}{l}1.201(1.111- \\
1.298)^{\star}\end{array}$ & $\begin{array}{l}1.891(1.734- \\
2.063)^{\star}\end{array}$ & $<0.001$ \\
\hline Model 1 & 1.000 (ref) & $0.989(0.914,1.070)$ & $1.051(0.969,1.139)$ & $1.575(1.439,1.724) \star$ & $<0.001$ \\
\hline \multicolumn{6}{|c|}{ Hypertension } \\
\hline Unadjusted & 1.000 (ref) & $\begin{array}{l}1.134(1.045- \\
1.230)^{\star}\end{array}$ & $\begin{array}{l}1.393(1.283- \\
1.512)^{\star}\end{array}$ & $\begin{array}{l}3.085(2.824- \\
3.371)^{\star}\end{array}$ & $<0.001$ \\
\hline Model 1 & 1.000 (ref) & $0.952(0.869,1.043)$ & $1.069(0.975,1.172)$ & $2.103(1.907,2.320)^{\star}$ & $<0.001$ \\
\hline \multicolumn{6}{|c|}{${ }^{*}$ means $p<0.001$} \\
\hline
\end{tabular}




\section{Discussion}

As far as we all known, this is the first large cross-sectional study to investigate the relationships between different TYG index, TG/HDL-c quartiles and prehypertension and hypertension in participants without DM2 from China, Tianjin. The current investigation showed that higher plasma TyG index and TG/HDL-c levels were associated with an increased risk of incident Prehypertension and Hypertension, independently of other known risk factors such as age, gender, smoking, drinking, marital status, Body Mass Index in this study. Furthermore, the association between TyG index, TG/HDL-C and age, HR, BMI, SBP, DBP, TC, TG, LDL-c and GLU were positive correlation, while HDL-c was negative correlation in spearman correlation analysis. Moreover, multiple logistics regression analysis suggested both the fourth and third quartiles of TyG index were the risk of prehypertension and hypertension. There was a significant difference in the risk of prehypertension and hypertension when comparing the highest TyG index (the fourth quartile) to the lowest TyG index (the first quartile) and corresponding ORs were 1.795(1.638,1.968) and 2.439(2.205,2.698), respectively. However, For TG/HDL-C, multiple logistics regression analysis suggested only the fourth quartile of TG/HDL-c was the risk of prehypertension and hypertension. The highest quartile to the lowest quartile of prehypertension and hypertension and corresponding ORs were 1.514(1.382,1.658) and 1.934(1.751,2.137), respectively. Furthermore, When comparing the fourth quartile to the first quartile of TyG index and TG/HDL-c, respectively, and both corresponding ORs of hypertension were higher than prehypertension.

Many studies demonstrated insulin resistance is associated with diabetes, obesity, coronary artery disease, hypertension and metabolic disorders, because of hyperinsulinaemia. [20-25]some people think the relevant reasons between insulin resistance and hypertension as follows, First, With the insulin increasing, the sympathetic nervous system and the renin-angiotensin-aldosterone system were activated, the corresponding systolic blood pressure and diastolic blood pressure were elevated. [20]Second, When insulin resistance induces hyperinsulinemia the sodium reabsorption from renal tubules is increased and leads to high blood pressure.[22, 26] Third, hyperglycemia makes the extracellular osmotic pressure higher than the intracellular osmotic pressure, in order to make a relative balance between extracellular and extracellular osmotic pressure, the water flows into the blood vessels, which increases the circulating blood volume and blood pressure in the blood vessels.[26]but no guideline suggests the certainly association between IR surrogate index and hypertension.

In a 9-year longitudinal population-based study, the TyG index has been reported as a good predictors for incident of hypertension, Cox regression analyses indicated that higher TyG index was associated with an increased risk of subsequent incident hypertension.[12] In one prospective cohort study, during the 20-year follow-up, High TG/HDL-c ratio in adolescence was associated with hypertension in early adulthood. [10] However, Jie Fan, MB et.al showed that MET-IR was significantly associated with prehypertension in subjects with normoglycemia, while TyG index and TG/HDL-c were not statistically significant.[6] In the present study, the logistic regression analysis showed that TyG index and TG/HDL-c were closely related to prehypertension and hypertension, we also found that the predictive ability of TyG index was better than TG/HDL-c in hypertension. In future, we will explore whether elevated TYG and TG/HDL-c can predict the Major Adverse Cardiovascular Events in hypertension individuals.

The disadvantange of this study is that we cannot show a certain causality association between prehypertension, hypertension and TyG index, TG/HDL-c. Another limitation is that we were not able to directly conduct hyperinsulinemic-euglycemic clamp (HIEC) technique of the insulin resistance in our study population, 
and to further compare the surrogate indexes with direct markers of insulin resistance. Moreover, the study population from China, Tianjin might limit the generalizability of TyG index, TG/HDL to other ethnic groups. Finally, less similar research about the relationship between prehypertension and hypertension with TyG index and TG/HDL-c in normoglycemic subjects results in a limited possible comparison of results. Therefore, further prospective and randomized studies will be required to confirm our findings.

\section{Conclusions}

The current investigation evidenced that elevated TyG index and TG/HDL-c levels were associated with an increased risk of incident Prehypertension and Hypertension, independently of other known risk factors such as age, gender, smoking, drinking, marital status, Body Mass Index in this study. Therefore, they have the potential to become cost-effective and complementary monitors in the hierarchical management of prehypertension and hypertension.

\section{Abbreviations}

DM2

type 2 diabetes mellitus

TYG

Triglyceride and glucose index

TG/HDL-C

triglyceride to high density lipoprotein cholesterol ratio

SBP

systolic blood pressure;

DBP

diastolic blood pressure;

TC

total cholesterol;

TG

triglycerides;

HDL-C

high density lipoprotein cholesterol;

LDL-C

low density lipoprotein cholesterol;

GLU

fasting glucose;

BMI

Body Mass Index;

HR

heart rate;

HIEC

hyperinsulinemic-euglycemic clamp technique

HOMA-IR 
Homeostasis model assessment for IR

IR

Insulin resistance

\section{Declarations}

Ethics approval and consent to participate: This study was performed in accordance with the Helsinki Declaration of 1964 and its later amendments and approved by the ethics committee of Tianjin Chest Hospital. All participants provided written informed consent to participate in the study.

Consent for publication: This section is not applicable.

Availability of data and materials: The data for the research were obtained from an existing database containing details held by the Early Screening and Comprehensive Intervention Program for High Risk Population of Cardiovascular Disease. The data are available upon request from the authors and permission from the Early Screening and Comprehensive Intervention Program for High Risk Population of Cardiovascular Disease.

Competing interests: The authors report no conflicts of interest.

Funding: This work was supported by the Department of Science and Technology of Tianjin city (15ZXHLSY00320 and 16ZXMJSY00140).

Authors Contributions: (I) Conception and design: H Cong, F Zhang, Y Zhang; (II) Administrative support: H Cong, Z Guo; (III) Provision of study materials or patients: Y Zhang, H Cong; (IV) Collection and assembly of data: $\mathrm{H}$ Cong, Y Zhang; (V) Data analysis and interpretation: F Zhang, M Ren, Hua Yang; (VI) Manuscript writing: All authors; (VII) Final approval of manuscript: All authors.

Acknowledgements: We would like to thank all the members of our research group for their enthusiastic participation in this study.

Author details: Fomin Zhang ${ }^{1}$, Yingyi Zhang ${ }^{2}$, Zhigang Guo ${ }^{2}$,Hua Yang ${ }^{2}$, Min Ren ${ }^{3}$, Xiaomeng Xing ${ }^{1}$, Hongliang Cong ${ }^{2}$; ${ }^{1}$ school of medicine, Tianjin Medical University, Tianjin 300070, China; ${ }^{2}$ Department of Cardiology, Tianjin Chest Hospital, Tianjin 300222, China; ${ }^{3}$ Department of Cardiovascular Surgery, Tianjin Chest Hospital, Tianjin 300222,China, ${ }^{4}$ Tianjin Cardiovascular Institute, Tianjin, 300222,China . Correspondence to: Hongliang Cong. Tianjin Chest Hospital, No. 261 Taierzhuang South Road, Jinnan District, Tianjin 300222, China. Email: hongliangcong@163.com. telephone number:+8613702102871

\section{References}

1. Messerli FH, Williams B, Ritz E: Essential hypertension. The Lancet 2007, 370(9587):591-603.

2. Lastra G, Dhuper S, Johnson MS, Sowers JR: Salt, aldosterone, and insulin resistance: impact on the cardiovascular system. Nat Rev Cardiol 2010, 7(10):577-584.

3. R. A. DeFronzo JDT, and R. Andres: Glucose clamp technique: a method for quantifying insulin secretion and resistance. American Journal of Physiology-Endocrinology and Metabolism 1979.

4. Bastard JP, Lavoie ME, Messier V, Prud'homme D, Rabasa-Lhoret R: Evaluation of two new surrogate indices including parameters not using insulin to assess insulin sensitivity/resistance in non-diabetic 
postmenopausal women: a MONET group study. Diabetes Metab 2012, 38(3):258-263.

5. Sanchez-Garcia A, Rodriguez-Gutierrez R, Mancillas-Adame L, Gonzalez-Nava V, Diaz Gonzalez-Colmenero A, Solis RC, Alvarez-Villalobos NA, Gonzalez-Gonzalez JG: Diagnostic Accuracy of the Triglyceride and Glucose Index for Insulin Resistance: A Systematic Review. Int J Endocrinol 2020, 2020:4678526.

6. Fan J, Gao ST, Wang LJ, Qian ZL, Zhou ZQ, Liu XZ: Association of Three Simple Insulin Resistance Indexes with Prehypertension in Normoglycemic Subjects. Metab Syndr Relat Disord 2019, 17(7):374-379.

7. Guerrero-Romero F, Simental-Mendia LE, Gonzalez-Ortiz M, Martinez-Abundis E, Ramos-Zavala MG, Hernandez-Gonzalez SO, Jacques-Camarena O, Rodriguez-Moran M: The product of triglycerides and glucose, a simple measure of insulin sensitivity. Comparison with the euglycemic-hyperinsulinemic clamp. $J$ Clin Endocrinol Metab 2010, 95(7):3347-3351.

8. Giannini C SN, Caprio S, et al. : The Triglyceride-to-HDL Cholesterol Ratio囚Association with insulin resistance in obese youths of different ethnic backgrounds. Diabetes Care 2011.

9. Simental-Mendia LE, Hernandez-Ronquillo G, Gamboa-Gomez Cl, Gomez-Diaz R, Rodriguez-Moran M, Guerrero-Romero F: The triglycerides and glucose index is associated with elevated blood pressure in apparently healthy children and adolescents. Eur J Pediatr 2019, 178(7):1069-1074.

10. Yeom H, Kim HC, Lee J-M, Jeon Y, Suh I: Triglyceride to high density lipoprotein cholesterol ratio among adolescents is associated with adult hypertension: the Kangwha study. Lipids in Health and Disease 2018, $17(1)$.

11. Liu XZ, Fan J, Pan SJ: METS-IR, a novel simple insulin resistance indexes, is associated with hypertension in normal-weight Chinese adults. J Clin Hypertens (Greenwich) 2019, 21(8):1075-1081.

12. Zheng R, Mao Y: Triglyceride and glucose (TyG) index as a predictor of incident hypertension: a 9-year longitudinal population-based study. Lipids Health Dis 2017, 16(1):175.

13. Zeng ZY, Liu SX, Xu H, Xu X, Liu XZ, Zhao XX: Association of triglyceride glucose index and its combination of obesity indices with prehypertension in lean individuals: A cross-sectional study of Chinese adults. $J$ Clin Hypertens (Greenwich) 2020, 22(6):1025-1032.

14. Xie Y, Guo R, Li Z, Guo X, Sun G, Sun Z, Zheng J, Sun Y, Zheng L: Temporal relationship between body mass index and triglyceride-glucose index and its impact on the incident of hypertension. Nutr Metab Cardiovasc Dis 2019, 29(11):1220-1229.

15. Bala C, Gheorghe-Fronea O, Pop D, Pop C, Caloian B, Comsa H, Bozan C, Matei C, Dorobantu M: The Association Between Six Surrogate Insulin Resistance Indexes and Hypertension: A Population-Based Study. Metab Syndr Relat Disord 2019, 17(6):328-333.

16. Jian S, Su-Mei N, Xue C, Jie Z, Xue-Sen W: Association and interaction between triglyceride-glucose index and obesity on risk of hypertension in middle-aged and elderly adults. Clin Exp Hypertens 2017, 39(8):732739.

17. Chobanian AV, Bakris GL, Black HR, Cushman WC, Green LA, Izzo JL, Jr., Jones DW, Materson BJ, Oparil S, Wright JT, Jr. et al: Seventh report of the Joint National Committee on Prevention, Detection, Evaluation, and Treatment of High Blood Pressure. Hypertension 2003, 42(6):1206-1252.

18. Simental-Mendia LE, Rodriguez-Moran M, Guerrero-Romero F: The product of fasting glucose and triglycerides as surrogate for identifying insulin resistance in apparently healthy subjects. Metab Syndr Relat Disord 2008, 6(4):299-304. 
19. Abbasi F, Reaven GM: Comparison of two methods using plasma triglyceride concentration as a surrogate estimate of insulin action in nondiabetic subjects: triglycerides $\mathrm{x}$ glucose versus triglyceride/high-density lipoprotein cholesterol. Metabolism 2011, 60(12):1673-1676.

20. Aroor AR, McKarns S, Demarco VG, Jia G, Sowers JR: Maladaptive immune and inflammatory pathways lead to cardiovascular insulin resistance. Metabolism 2013, 62(11):1543-1552.

21. Babic N, Valjevac A, Zaciragic A, Avdagic N, Zukic S, Hasic S: The Triglyceride/HDL Ratio and Triglyceride Glucose Index as Predictors of Glycemic Control in Patients with Diabetes Mellitus Type 2. Med Arch 2019, 73(3):163-168.

22. Hall JE, do Carmo JM, da Silva AA, Wang Z, Hall ME: Obesity, kidney dysfunction and hypertension: mechanistic links. Nat Rev Nephrol 2019, 15(6):367-385.

23. Jia G, DeMarco VG, Sowers JR: Insulin resistance and hyperinsulinaemia in diabetic cardiomyopathy. Nat Rev Endocrinol 2016, 12(3):144-153.

24. Wang L, Cong HL, Zhang JX, Hu YC, Wei A, Zhang YY, Yang H, Ren LB, Qi W, Li WY et al: Triglyceride-glucose index predicts adverse cardiovascular events in patients with diabetes and acute coronary syndrome. Cardiovasc Diabetol 2020, 19(1):80.

25. Zuo Y, Wang A, Chen S, Tian X, Wu S, He Y: Distinct eGFR trajectories are associated with risk of myocardial infarction in people with diabetes or prediabetes. J Diabetes 2021, 13(2):124-133.

26. Ohishi M: Hypertension with diabetes mellitus: physiology and pathology. Hypertens Res 2018, 41(6):389393.

\section{Tables}




\begin{tabular}{|c|c|c|c|c|}
\hline variables & $\begin{array}{l}\text { Normotension } \\
(n=7248)\end{array}$ & $\begin{array}{l}\text { Prehypertension } \\
(n=13343)\end{array}$ & $\begin{array}{l}\text { Hypertension } \\
(n=11533)\end{array}$ & P-value \\
\hline Age & $52.1 \rrbracket 44.8,61.7 \rrbracket$ & $56.6 ه 47.9,65.5 \rrbracket$ & $51.5 \rrbracket 43.3,61.9 \rrbracket$ & $<0.001$ \\
\hline Gender(men) & $2045(28.2 \%)$ & $5578(41.8 \%)$ & $4751(41.2 \%)$ & $<0.001$ \\
\hline Marital status & & & & $<0.001$ \\
\hline Not married & $108(1.5 \%)$ & $120(0.9 \%)$ & $115(1.0 \%)$ & \\
\hline Married & $6928(95.6 \%)$ & $12879(96.5 \%)$ & $10743(93.2 \%)$ & \\
\hline Divorced & $78(1.1 \%)$ & $85(0.6 \%)$ & $97(0.8 \%)$ & \\
\hline Widowed & $134(1.8 \%)$ & $259(1.9 \%)$ & $578(5.0 \%)$ & \\
\hline Smoking & $890(12.3 \%)$ & $1785(13.4 \%)$ & $2440(21.2 \%)$ & $<0.001$ \\
\hline Drinking & $1101(15.2 \%)$ & $2237(16.8 \%)$ & $3113(27.0 \%)$ & $<0.001$ \\
\hline HR(bpm) & $72.5(68.0,78.5)$ & $73.0(70.0,78.5)$ & $75.0(69.0,82.0)$ & $<0.001$ \\
\hline BMI(kg/m2) & $23.6(22.0,25.6)$ & $24.6(22.9,26.7)$ & $26.3(24.1,28.7)$ & $<0.001$ \\
\hline $\mathrm{SBP}(\mathrm{mmHg})$ & $112.5(107.0,116.5)$ & $127.0(122.0,131.0)$ & $147.5(139.0,160.0)$ & $<0.001$ \\
\hline $\mathrm{DBP}(\mathrm{mmHg})$ & $70.5(65.5,74.00)$ & $79.0(73.5,82.0)$ & $85.0(78.0,92.0)$ & $<0.001$ \\
\hline $\mathrm{TC}(\mathrm{mg} / \mathrm{dl})$ & $163.32(139.83,190.47)$ & $171.39(145.33,192.31)$ & $176.16(147.17,209.19)$ & $<0.001$ \\
\hline $\mathrm{TG}(\mathrm{mg} / \mathrm{dl})$ & $119.48(93.81,147.80)$ & $129.21(98.24,177.89)$ & $140.72(103.55,198.24)$ & $<0.001$ \\
\hline $\mathrm{HDL-c}(\mathrm{mg} / \mathrm{dl})$ & $53.41 \rrbracket 46.44,65.02 \rrbracket$ & $53.02 \rrbracket 45.66,65.79 \rrbracket$ & $51.47 \rrbracket 43.34,61.92 \rrbracket$ & $<0.001$ \\
\hline LDL-c(mg/dl) & $96.75(76.63,115.33)$ & $104.49(81.27,116.87)$ & $107.50(82.04,130.03)$ & $<0.001$ \\
\hline $\mathrm{GLU}(\mathrm{mg} / \mathrm{dl})$ & $97.20(90.00,104.40)$ & $97.20(91.80,104.40)$ & $102.60(95.40,109.80)$ & $<0.001$ \\
\hline TyG & $8.65(8.41,8.90)$ & $8.75(8.46,9.10)$ & $8.88(8.56,9.24)$ & $<0.001$ \\
\hline TG/HDL & $2.23 \otimes 1.61,2.96 \rrbracket$ & $2.47(1.74,3.54)$ & $2.78(2.86,4.14)$ & $<0.001$ \\
\hline \multicolumn{5}{|c|}{$\begin{array}{l}\text { SBP: systolic blood pressure; DBP: diastolic blood pressure; TC: total cholesterol; TG: triglycerides; HDL-c: } \\
\text { high density lipoprotein cholesterol; LDL-C: low density lipoprotein cholesterol; GLU: fasting glucose;. BMI: } \\
\text { Body Mass Index; HR: heart rate; age, HR, BMI, SBP, DBP, TC, TG, HDL-C, LDL-c, GLU were described as } \\
\text { medians [interquartile range (IQR)]; gender, marital status, smoking, drinking as frequencies [percentages } \\
\text { (\%)]. }\end{array}$} \\
\hline
\end{tabular}




\begin{tabular}{|c|c|c|c|c|}
\hline \multirow[b]{2}{*}{ parameters } & \multicolumn{2}{|c|}{ TyG $\quad$ TG/HDL } & & \\
\hline & $r \quad P$ value $r$ & $p$ value & & \\
\hline Age & $0.078<0.001$ & & 0.027 & $<0.001$ \\
\hline SBP & $0.184<0.001$ & & 0.15 & $<0.001$ \\
\hline DBP & $0.15<0.001$ & & 0.166 & $<0.001$ \\
\hline TC & $0.155<0.001$ & & 0.105 & $<0.001$ \\
\hline TG & $0.969<0.001$ & & 0.848 & $<0.001$ \\
\hline HDL-c & $-0.148<0.001$ & & -0.592 & $<0.001$ \\
\hline LDL-c & $0.155<0.001$ & & 0.105 & $<0.001$ \\
\hline GLU & $0.350<0.001$ & & 0.157 & $<0.001$ \\
\hline BMI & $0.226<0.001$ & & 0.249 & $<0.001$ \\
\hline $\mathrm{HR}$ & $0.098<0.001$ & & 0.067 & $<0.001$ \\
\hline \multicolumn{5}{|c|}{$\begin{array}{l}\text { TyG: fasting triglyceride and glucose; TG/HDL-c: triglyceride to high density lipoprotein cholesterol ; SBP: } \\
\text { systolic blood pressure; DBPP: diastolic blood pressure; TC: total cholesterol; TG: triglycerides; HDL-- high } \\
\text { density lipoprotein cholesterol; LDL-c: low density lipoprotein cholesterol; GLU: fasting glucose;. BMI: Body } \\
\text { Mass Index; HR: heart rate; }\end{array}$} \\
\hline
\end{tabular}


Table 3 clinical/laboratory parameters Univariate logistic analysis with the risk of prehypertension and hypertension

\begin{tabular}{|lllll|}
\hline variables & prehypertension & & hypertension & P values \\
\hline Age & OR $(95 \% \mathrm{Cl})$ & P values & OR(95\%Cl) & $<0.001$ \\
\hline Gender(men) & $1.031(1.028,1.034)$ & $<0.001$ & $1.094(1.091,1.098)$ & $<0.001$ \\
\hline Marital status & $1.828(1.718,1.944)$ & $<0.001$ & $1.782(1.673,1.899)$ & 0.005 \\
\hline married & $1.673(1.288,2.173)$ & $<0.001$ & $1.456(1.118,1.897)$ & 0.444 \\
\hline divorced & $0.981(0.656,1.467)$ & 0.925 & $1.168(0.785,1.738)$ & $<0.001$ \\
\hline widowed & $1.740(1.247,2.428)$ & 0.001 & $4.051(2.933,5.595)$ & $<0.001$ \\
\hline Smoking & $1.103(1.012,1.202)$ & $<0.001$ & $1.917(1.764,2.083)$ & $<0.001$ \\
\hline Drinking & $1.125(1.040,1.217)$ & 0.003 & $2.064(1.913,2.228)$ & $<0.001$ \\
\hline BMI & $1.121(1.110,1.132)$ & $<0.001$ & $1.300(1.287,1.314)$ & $<0.001$ \\
\hline TyG & $1.710(1.605,1.822)$ & $<0.001$ & $2.873(2.691,3.068)$ & $<0.001$ \\
\hline TG/HDL & $1.152(1.130,1.174)$ & $<0.001$ & $1.293(1.268,1.318)$ & BMl: \\
\hline $\begin{array}{l}\text { TyG: fasting triglyceride and glucose; TG/HDL-c: triglyceride to high density lipoprotein cholesterol } \\
\text { Body Mass Index; }\end{array}$ & & & \\
\hline
\end{tabular}

Table 4 Association between the TyG index quartiles and risk of incident prehypertension and hypertension

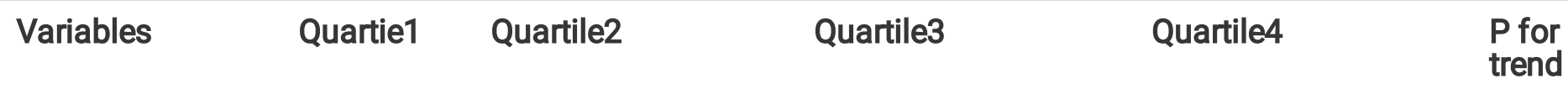

\section{Prehypertension}

\begin{tabular}{|c|c|c|c|c|c|}
\hline Unadjusted & 1.000 (ref) & $1.017(0.943,1.096)$ & $1.229(1.136,1.328)^{\star}$ & $2.136(1.956,2.333) \star$ & $<0.001$ \\
\hline Model 1 & 1.000(ref) & $0.955(0.884,1.032)$ & $1.113(1.027,1.207) *$ & $1.876(1.713,2.055)^{\star}$ & $<0.001$ \\
\hline \multicolumn{6}{|c|}{ Hypertension } \\
\hline Unadjusted & 1.000(ref) & $\begin{array}{l}1.157(1.066- \\
1.256)^{\star}\end{array}$ & $\begin{array}{l}1.845(1.699- \\
2.003)^{\star}\end{array}$ & $\begin{array}{l}3.889(3.551- \\
4.258)^{\star}\end{array}$ & $<0.001$ \\
\hline Model 1 & 1.000 (ref) & $0.973(0.889,1.066)$ & $1.377(1.257,1.510) *$ & $2.701(2.445,2.983) *$ & $<0.001$ \\
\hline
\end{tabular}




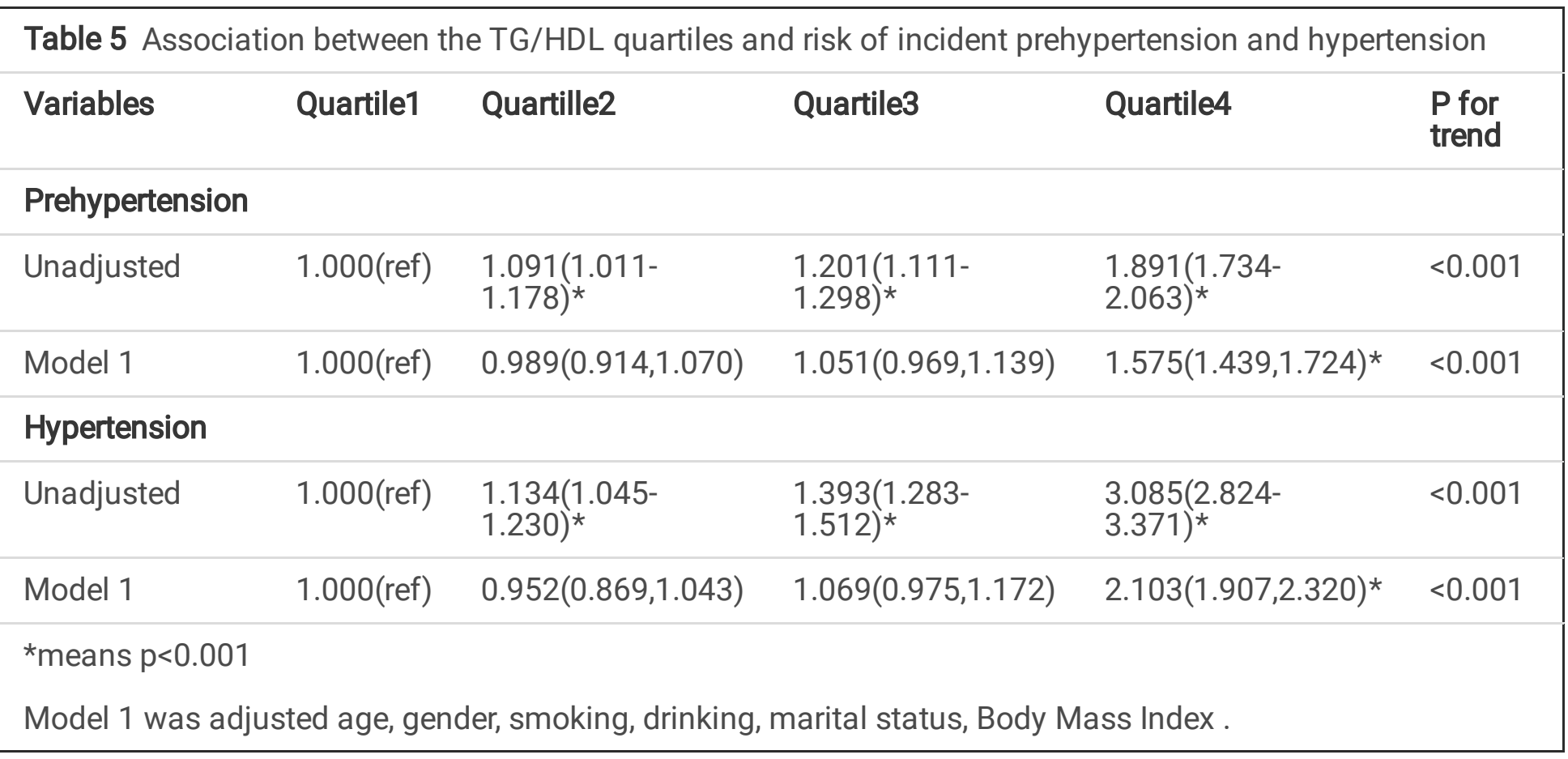

\section{Figures}

TYG

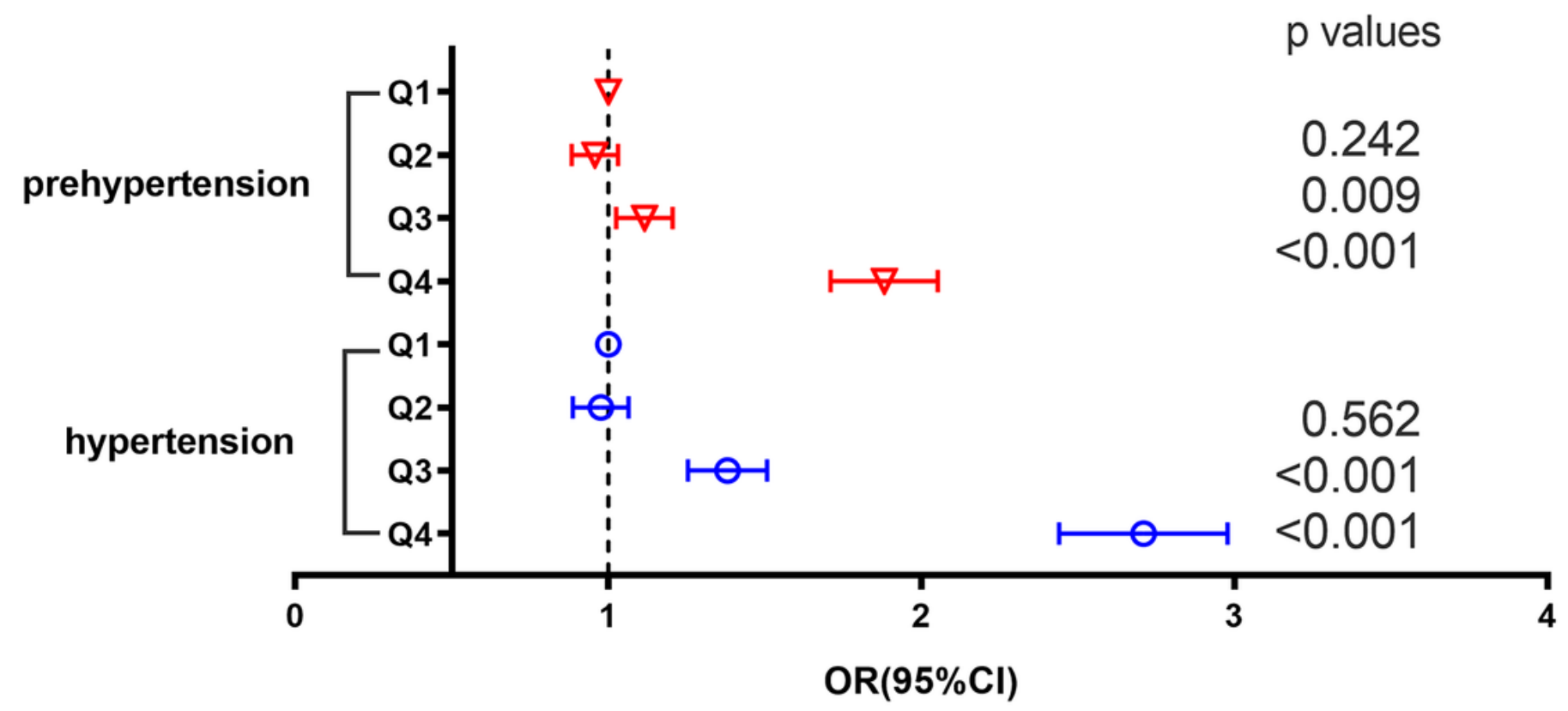

Figure 1

the OR between the TYG index quartiles and risk of incident prehypertension and hypertension 


\section{TG/HDL}

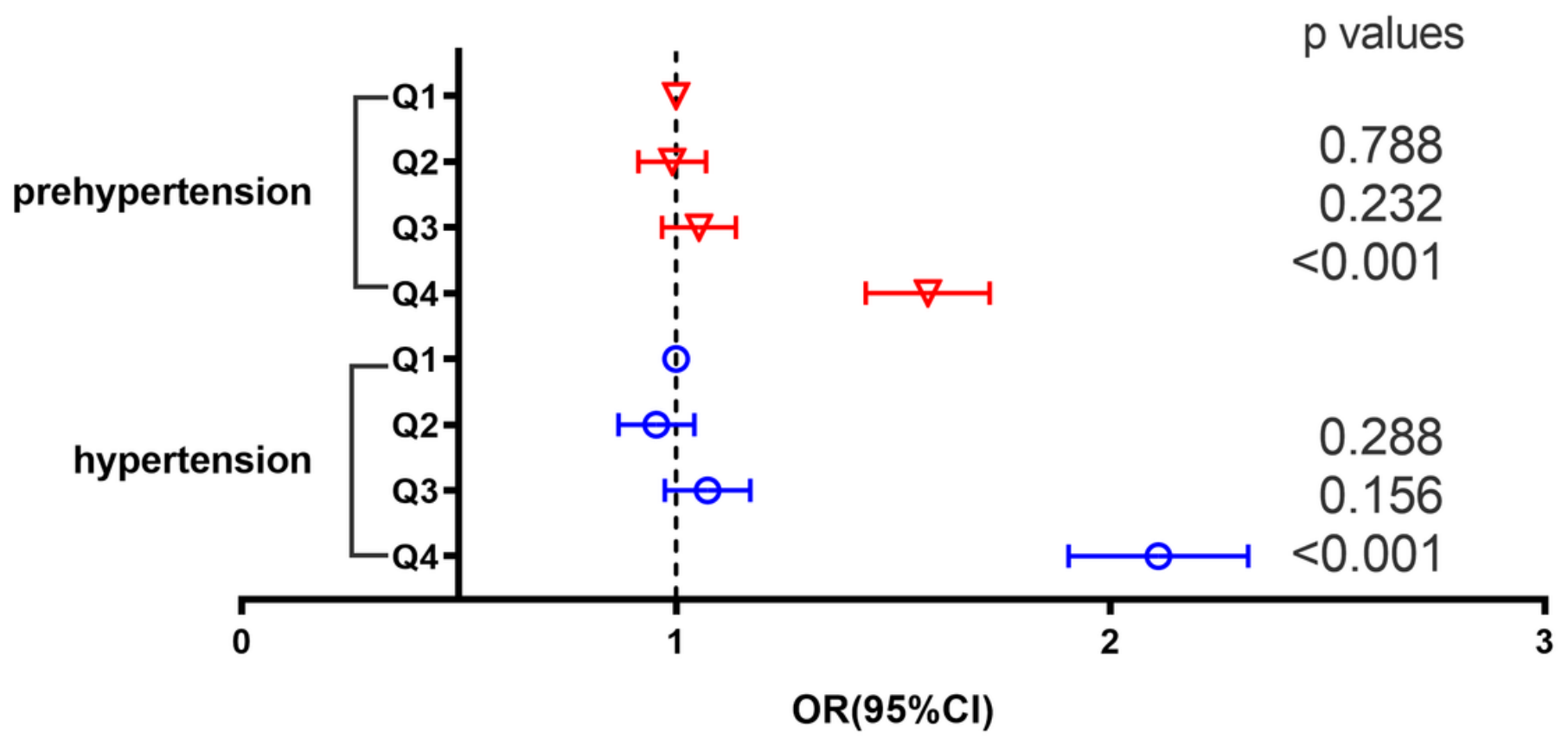

Figure 2

the OR between the TG/HDL-c quartiles and risk of incident prehypertension and hypertension 